\title{
Analisis Perbandingan Waktu Perjalanan dan Biaya antara Kendaraan Pribadi dan Transjakarta menggunakan Metode PCI (Studi Kasus : TJ Koridor IX Pinang Ranti-Pluit)
}

\author{
Comparative Analysis of Travel Time and Cost between Private Vehicles and \\ Transjakarta using the PCI method (Case Study: TJ Corridor IX Pinang Ranti-Pluit)
}

\author{
Adita Utami ${ }^{1^{*}}$ dan William Kurnia Rubin Natio ${ }^{2}$ \\ ${ }^{1,2}$ Program Studi Teknik Sipil, Fakultas Perencanaan Infrastruktur, Universitas Pertamina - Jl. Teuku Nyak \\ Arief, Simprug, Jakarta Selatan, DKI Jakarta 12220
}

\begin{tabular}{|c|c|}
\hline ARTICLE INFO & ABSTRAK \\
\hline $\begin{array}{l}\text { Article history } \\
\text { Received : } 05 \text { Agustus } 2021 \\
\text { Revised : } 10 \text { September } 2021 \\
\text { Accepted : 22 September } 2021\end{array}$ & $\begin{array}{l}\text { Pemilihan penggunaan moda transportasi untuk melakukan perjalanan dari asal ke } \\
\text { tujuan dipengaruhi oleh berbagai macam faktor. Faktor yang diperhatikan antara } \\
\text { lain waktu tempuh, Biaya Operasional Kendaraan (BOK) dan nilai waktu } \\
\text { perjalanan. Untuk memperkirakan mode apa yang akan dipilih oleh masyarakat } \\
\text { untuk bepergian, penelitian ini membahas tentang analisis perbandingan waktu } \\
\text { tempuh dan biaya moda transportasi umum yaitu transjakarta dan mobil pribadi. }\end{array}$ \\
\hline $\begin{array}{l}\text { DOI : } \\
\text { https://doi.org/10.33366/rekabua } \\
\text { na.v6i2.2649 }\end{array}$ & $\begin{array}{l}\text { Penelitian ini berlokasi di provinsi DKI Jakarta tepatnya pada koridor IX } \\
\text { transjakarta Pinang Ranti-Pluit. Pengukuran waktu perjalanan dilakukan dengan } \\
\text { cara menaiki masing-masing moda dengan rute dan waktu yang sama. Data } \\
\text { sekunder sebagai bahan perhitungan, diperoleh dari instansi yang terkait dengan }\end{array}$ \\
\hline $\begin{array}{l}\text { Keywords : } \\
\text { BOK; cost; comparative; PCI; } \\
\text { traveling time }\end{array}$ & $\begin{array}{l}\text { penelitian ini. Analisis Biaya Operasional Kendaraan (BOK) dalam penelitian ini } \\
\text { menggunakan Metode Pacific Consultants International (PCI) Hasil penelitian } \\
\text { menunjukkan bahwa pada jam sibuk penggunaan Transjakarta lebih efektif secara } \\
\text { waktu karena waktu tempuh yang diperlukan lebih cepat } 11 \text { menit dibandingkan } \\
\text { dengan kendaraan pribadi. Kemudian untuk biaya yang dikeluarkan juga lebih }\end{array}$ \\
\hline $\begin{array}{l}\text { *e-mail corresponding author : } \\
\text { adita.utami@ universitasperta }\end{array}$ & $\begin{array}{l}\text { efisien menggunakan Transjakarta dengan biaya sebesar Rp } 3.500 \text { sekali perjalanan. } \\
\text { Sedangkan jika dibandingkan dengan menggunakan kendaraan pribadi sebesar Rp }\end{array}$ \\
\hline mina.c.id & $\begin{array}{l}14.784 \text { perorang dengan kapasitas mobil penumpang sebanyak } 7 \text { orang. Pada masa } \\
\text { pandemic covid- } 19 \text {, terdapat ketentuan batas kapasitas mobil penumpang sebanyak } \\
4 \text { orang. Sehingga biaya menggunakan kendaraan pribadi perorangnya dapat } \\
\text { mencapai Rp. } 25.871 \text {. }\end{array}$ \\
\hline
\end{tabular}

\section{PENERBIT}

\section{UNITRI PRESS}

J1. Telagawarna, Tlogomas-

Malang, 65144, Telp/Fax:

$0341-565500$

\section{cc) (i) (2)}

This is an open access article under the Creative Commons Attribution-ShareAlike $\quad \mathbf{4 . 0}$ International License. Any further distribution of this work must maintain attribution to the author(s) and the title of the work, journal citation and DOI. CC-BY-SA

\begin{abstract}
Selection of the use of transportation modes to travel from origin to destination is influenced by various factors. Factors that must be considered include travel time, vehicle operating costs (VOK), and the value of travel time. The purpose of this study is to determine which model will be chosen by the user to travel and discusses the comparative analysis of travel time and cost of public transportation modes, namely Transjakarta and private cars. This research was conducted in DKI Jakarta, precisely in the Transjakarta corridor IX Pinang Ranti-Pluit. Measurement of travel time is done by riding each mode with the same route and time. Secondary data as calculation material was obtained from agencies related to this research. This study analyzes Vehicle Operational Costs (VOK) using the Pacific Consultants International (PCI) method. The results showed that during peak hours, the use of Transjakarta was more effective in terms of time because the travel time required was 11 minutes faster than in private vehicles. Then for the costs incurred, it is also more efficient to use Transjakarta at the cost of Rp. 3,500 per trip. Meanwhile, using a private vehicle of Rp. 14,784 per person with a passenger car capacity of 7 people. During the COVID-19 pandemic, there was a provision for a passenger car capacity limit of 4 people. So the cost of using a private vehicle per person can reach $R p .25,871$.
\end{abstract} Kendaraan Pribadi dan Transjakarta menggunakan Metode PCI (Studi Kasus : TJ Koridor IX Pinang Ranti-Pluit). Reka Buana : Jurnal Ilmiah Teknik Sipil dan Teknik Kimia, 6(2), 150-159. doi:https://doi.org/10.33366/rekabuana.v6i2.2649 


\section{PENDAHULUAN}

DKI Jakarta merupakan provinsi dengan jumlah kepadatan penduduk tertinggi di Indonesia, menurut Badan Pusat Statistik (BPS) pada tahun 2019 kepadatan itu mencapai angka 15.938 jiwa per kilometer persegi. Menjadi provinsi terpadat dengan pertumbuhan penduduk yang cepat menjadikan DKI Jakarta sebagai kota metropolitan yang memiliki mobilitas yang tinggi. Mobilitas yang tinggi ini dapat terlihat dari kemacetan yang selalu meningkat yang diakibatkan bertambahnya jumlah kendaraan yang melintas serta tidak diimbangi oleh pertumbuhan pembangunan prasarana jalan dan prasarana transportasi lain [1], [2]. Berdasarkan pernyataan di atas maka dapat disimpulkan bahwa pertumbuhan penduduk yang kian meningkat, berbanding lurus dengan peningkatan mobilitas dan dorongan akses ke tengah kota

Untuk mensupport mobilitas mayarakat, salah satu transportasi umum yang ditawarkan oleh pemprov DKI Jakarta adalah Transjakarta yang merupakan sistem Bus Rapid Transit (BRT) [3] dan sudah mulai beroperasi sejak 2004. Transjakarta kini menjadi pilihan kendaraan umum yang nyaman untuk dipakai oleh masyarakat Jakarta yang dapat menyerap penumpang terbanyak kedua yaitu sebanyak sekitar 144 juta pengguna (pada tahun 2017) dan hanya berada dibawah dari KRL [4]. Peningkatan kualitas ini selain untuk meningkatkan kenyamanan bagi penggunanya juga dilakukan dalam upaya untuk menarik minat masyarakat agar lebih memilih menggunakan kendaraan umum dibandingkan kendaraan pribadi [5]. Sebagai transportasi umum di Jakarta terdapat beberapa kelebihan yang dimiliki oleh Transjakarta dibanding dengan kendaraan lain salah satunya tarif yang lebih murah yaitu Rp 3.500 untuk sekali perjalanan.

Transjakarta koridor IX merupakan koridor dengan rute terpanjang yang dimiliki oleh Transjakarta. Koridor IX ini memiliki rute dengan panjang total $28,8 \mathrm{~km}$ dan di dalamnya terdapat 26 halte, serta melewati kelima kota administratif di Jakarta yang kedua ujungnya berada di Jakarta Selatan (Halte Pinang Ranti) dan Jakarta Utara (Halte Pluit). Namun pada koridor ini, kemacetan masih menjadi hal yang tidak mungkin dihindarkan karena meningkatnya jumlah kendaraan bermotor di Jakarta, jika dilihat dari BPS pada tahun 2012 hingga 2016 saja terjadi peningkatan jumlah kendaraan bermotor sebesar $5,35 \%$. Kemacetan yang salah satunya merupakan imbas dari banyaknya pengguna kendaraan pribadi ini, membuat pemerintah DKI Jakarta harus meningkatkan pelayanan pada transportasi umum yang mereka miliki. Pemerintah DKI Jakarta selalu berupaya untuk melakukan peningkatan baik dari sisi jumlah moda, rute, ataupun performa seperti keamanan, kenyamanan, kecepatan dari kendaraan umum untuk menarik para pengguna kendaraan pribadi agar mau beralih menggunakan kendaraan umum. Tujuan dilakukannya penelitian ini yaitu untuk memberikan gambaran kepada masyarakat terkait efisiensi pemilihan moda ditinjau dari segi biaya dan waktu. Oleh karena itu perlu dilakukan analisis perbandingan waktu tempuh dan biaya antara transjakarta dan kendaraan pribadi (mobil penumpang). 


\section{METODE PENELITIAN}

Dalam melaksanakan rencana penelitian dan untuk mempermudah memecahkan masalah yang dihadapi, maka perlu diuraikan terlebih dahulu tahapan yang diperlukan. Tahapan tersebut terdapat pada bagan alir Gambar 1.

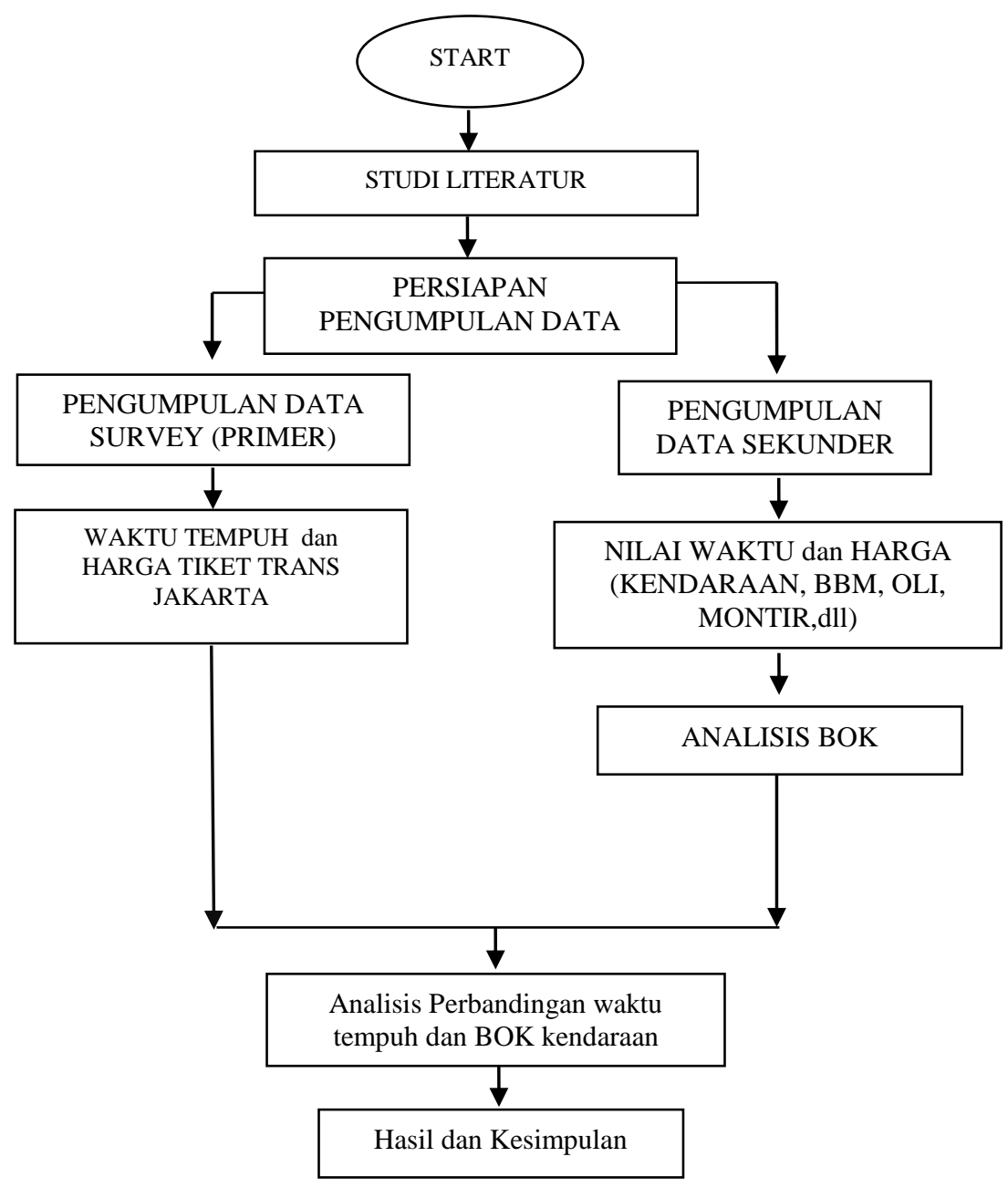

Gambar 1. Bagan alir penelitian

\subsection{Studi Terdahulu}

Terdapat beberapa penelitian terdahulu yang pernah dilakukan untuk menganalisis biaya operasional kendaraan. Terdapat beberapa metode yang dapat digunakan untuk melakukan analisis Biaya Operasional Kendaraan (BOK) seperti metode $N d$ Lea Consultant dan metode Pacific Consultant International (PCI). Pada penelitian oleh Nurahmi (2012) [6], metode Nd Lea Consultant digunakan untuk melakukan analisis ekonomi pembangunan frontage di Surabaya. Pada penelitian lain terdapat penelitian yang dilakukan oleh Rahman (2012) [7] metode PCI digunakan untuk menganalisis Biaya Operasional Kendaraan pada transportasi umum di kota Poso. Ditinjau dari kesesuaian obyek penelitian, maka pada penelitian ini metode PCI digunakan untuk menganalisis BOK Tranjakarta. 
Berdasarkan penelitian Almansyah (2018) [8], dalam melakukan analisis BOK menggunakan metode PCI, diperlukan beberapa variabel penelitian yang dapat mempengaruhi besarnya nilai BOK yang dihasilkan. Variabel tersebut seperti: data kecepatan kendaraan, harga (kendaraan, oli, bbm, montir, suku bunga, dan depresiasi kendaraan). Selain melakukan analisis BOK, dilakukan pula survei kecepatan tempuh untuk kendaraan umum dan kendaraan pribadi. Selanjutnya kecepatan tempuh tersebut dibandingkan untuk mendapatkan selisih nilai waktu antara mobil pribadi dan transjakarta.

\subsection{Lokasi Penelitian}

Lokasi penelitian merupakan Koridor IX Transjakarta (Pinang Ranti - Pluit). Koridor IX Transjakarta ini mulai beroperasi sejak 31 Desember 2010 dengan panjang rute sepanjang 29,9 km, melalui 27 halte dan 5 halte transit. Rute Koridor IX dari Pinang Ranti menuju Pluit dapat dilihat pada Tabel 1, sedangkan untuk rute perjalanan dapat dilihat pada Gambar 2.
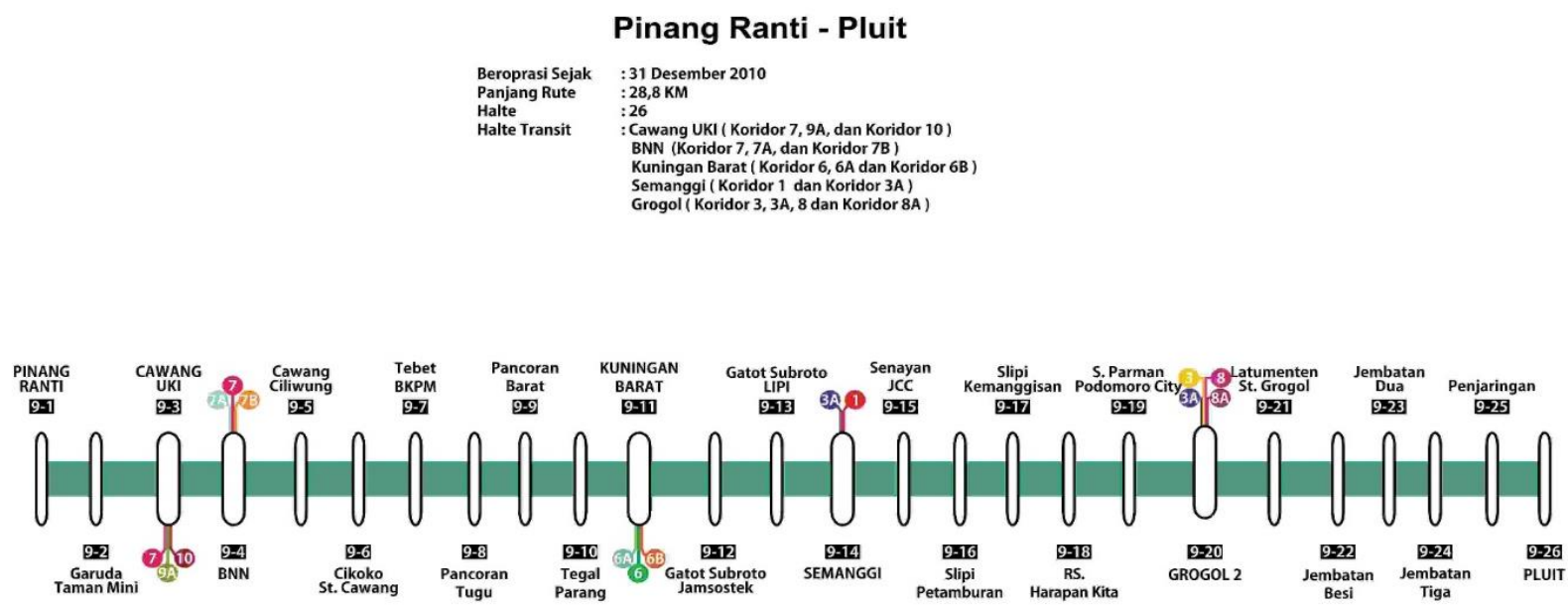

Gambar 2. Gambar Posisi Halte Transjakarta Koridor IX

(Sumber: transjakarta.co.id, diakses pada Senin 17 Februari 2021)

Tabel 2. Rute transjakarta koridor IX

\begin{tabular}{cccc}
\hline No & Halte & No & Halte \\
\hline 1 & Pinang Ranti & 14 & Semanggi \\
2 & Garuda Taman Mini & 15 & Senayan JCC \\
3 & Cawang UKI & 16 & Slipi Petamburan \\
4 & BNN & 17 & Slipi Kemanggisan \\
5 & Cawang Ciliwung & 18 & RS. Harapan Kita \\
6 & Cikoko St. Cawang & 19 & S.Parman Podomoro City \\
7 & Tebet BKPM & 20 & Grogol 2 \\
8 & Pancoran Tugu & 21 & Latumenten St. Grogol \\
9 & Pancoran Barat & 22 & Jembatan Besi \\
10 & Tegal Parang & 23 & Jembatan Dua \\
11 & Kuningan Barat & 24 & Jembatan Tiga \\
12 & Gatot Subroto Jamsostek & 25 & Penjaringan \\
13 & Gatot Subtroto LIPI & 26 & Pluit \\
\hline
\end{tabular}




\subsection{Pengumpulan Data}

Pada penelitian ini dilakukan pengumpulan data berupa data primer dan data sekunder. Data primer berupa travel time didapat dengan cara melakukan survei travel time Transjakarta. Survei dilakukan untuk mendapatkan jumlah waktu tempuh yang dibutuhkan setiap armada selama perjalanan dari halte Pinang Ranti menuju halte Pluit dan kembali ke halte Pinang Ranti. Survei dilakukan dengan cara menghitung jumlah seluruh waktu tempuh yang diperlukan selama perjalanan dan ditambah dengan waktu tundaan atau waktu henti yang terjadi selama perjalanan [9], [10].

Untuk data sekunder didapat dari instansi ataupun literatur - literatur yang bisa digunakan untuk menunjang dan memvalidasi hasil analisis dari survei yang sudah dilaksanakan. Data sekunder yang diperlukan yaitu: harga tiket TJ, harga (kendaraan, oli, bblm, onderdil, dll) serta besaran nilai waktu.

\subsection{Biaya Operasional Kendaraan}

Biaya Operasional Kendaraan (BOK) adalah biaya yang harus dikeluarkan untuk mengoperasikan kendaraan berdasarkan perjalanannya. Untuk menghitung BOK yang diperlukan oleh kendaraan pribadi pada penelitian ini digunakan parameter-parameter dari metode PCI (Pacific Consultant International)[11], [12]. Parameter-parameter yang dihitung dapat dilihat pada persamaan dibawah ini :

1. Konsumsi Bahan Bakar

Sedan $(\mathrm{PC}) \quad: \quad \mathrm{Y}=0.03719 \mathrm{~S} * \mathrm{~S}-4.19966 \mathrm{~S}+175.9911$

Keterangan:

$\mathrm{Y}=$ Konsumsi bahan bakar (liter/1000 km)

$\mathrm{S} \quad=$ Running Speed $(\mathrm{Km} / \mathrm{Jam})$

2. Konsumsi Oli Mesin

Sedan $(\mathrm{PC}) \quad: \mathrm{Y}=0.00025 \mathrm{~S} * \mathrm{~S}-0.02664 \mathrm{~S}+1.441710$

3. Konsumsi Pemakaian Ban

Sedan $(\mathrm{PC}) \quad: \mathrm{Y}=(0.0008848 \mathrm{~S}-0.004533)$.

Keterangan:

$\mathrm{Y}^{\prime} \quad=\mathrm{Y}^{*}$ jumlah ban*harga ban/1000km

4. Biaya Pemeliharan (Onderdil)

Sedan (PC) : Y=(0.0000064S+0.0005567)

Keterangan:

$\mathrm{Y}^{\prime} \quad=\mathrm{Y}^{*}$ nilai kendaraan $(/ 1000 \mathrm{~km})$

$\mathrm{S}=$ Running Speed $(\mathrm{Km} / \mathrm{Jam})$ 
5. Biaya Pemeliharaan (Pekerja)

Sedan $(\mathrm{PC}) \quad$ : $\mathrm{Y}=(0.00362 \mathrm{~S}+0.36267)$

Keterangan:

$\mathrm{Y}^{\prime} \quad=\mathrm{Y}^{*}$ ongkos mekanik perjam $($ per $1000 \mathrm{~km})$

6. Penyusutan Kendaraan

Sedan $\quad: Y=\frac{1}{2.5 S+125}$

Keterangan :

$\mathrm{Y} \quad=$ Penyusutan kendaraan per $1000 \mathrm{~km}$, dikalikan dengan harga kendaraan

$\mathrm{S} \quad=$ Running Speed $(\mathrm{Km} / \mathrm{Jam})$

7. Suku Bunga

Sedan

$$
: Y=\frac{120}{500 S}
$$

Keterangan :

$\mathrm{Y}=$ Penyusutan kendaraan per $1000 \mathrm{~km}$, dikalikan dengan harga kendaraan

$\mathrm{S} \quad=$ Running Speed $(\mathrm{Km} / \mathrm{Jam})$

8. Asuransi

Sedan

$$
: Y=\frac{35 \times 0.5}{500 \mathrm{~S}}
$$

Keterangan :

$\mathrm{Y}=$ Penyusutan kendaraan per $1000 \mathrm{~km}$, dikalikan dengan harga kendaraan

$\mathrm{S} \quad=$ Running Speed $(\mathrm{Km} / \mathrm{Jam})$

\section{HASIL DAN PEMBAHASAN}

\subsection{Waktu Tempuh}

Survei waktu tempuh dilaksanakan oleh empat orang surveyor yang dibagi ke dua armada. Surveyor pertama menggunakan mobil pribadi dan surveyor kedua menggunakan transjakarta. Survei dilaksanakan pada hari Rabu 6 Januari 2021 dengan waktu pelaksanaan yang sama dan titik pemberangakatan yang sama pula. Hari Rabu survei dilaksanakan pada pukul 07.38 pagi untuk mewakili jam sibuk pagi hari dan dilaksanakan pada pukul 17.00 sore untuk mewakili jam sibuk sore hari. Rute perjalanan yang dilalui oleh kendaraan pribadi mengikuti rute dari Transjakarta rute Pinang Ranti-Pluit namun hanya terdapat perbedaan saat menuju halte Pancoran Tugu. Saat menuju halte Pancoran Tugu, kendaraan pribadi akan melewati flyover sehingga tidak terkena efek lampu lalu lintas, sementara Transjakarta tidak melalui flyover karena halte Pancoran Tugu berada dibawah flyover. Survei dimulai dengan menghitung waktu perjalanan rute Pinang Ranti-Pluit. Hasil survei total waktu tempuh pada hari Rabu dapat dilihat pada Tabel 2. 
Tabel 2. Rekapitulasi hasil survei waktu tempuh

\begin{tabular}{ccc}
\hline Waktu & Transjakarta & Mobil Pribadi \\
\hline Pinang Ranti - Pluit (pagi) & 01.15 .37 & 01.34 .10 \\
Pluit - Pinang Ranti (pagi) & 01.19 .41 & 01.32 .07 \\
Pinang Ranti - Pluit (sore) & 01.10 .25 & 01.21 .15 \\
Pluit - Pinang Ranti (sore) & 01.07 .35 & 01.25 .37 \\
\hline
\end{tabular}

\subsection{Biaya Operasional Kendaran (BOK)}

Untuk mengetahui biaya yang dikeluarkan dalam penggunaan kendaraan pribadi, dilakukan perhitungan biaya opersional kendaraan dengan metode PCI (Pasific Consultant International) [13], [14]. Dimana metode PCI memiliki beberapa faktor yang dihitung yaitu konsumsi bahan bakar, konsumsi oli mesin, konsumsi pemakaian ban, biaya pemeliharaan (onderdil), biaya pemeliharaan (upah pekerja), penyusutan kendaraan, persamaan suku bunga, persamaan asuransi. Lalu setelah didapatkan nilai dari masingmasing faktor, dilakukan penyesuaian dengan rute Pinang Ranti-Pluit.

Biaya yang dikeluarkan oleh kendaraan pribadi ini bergantung terhadap tipe kendaraan yang digunakan karena komponen-komponen yang digunakan berbeda di tiap kendaraan seperti bahan bakar yang digunakan, oli mesin yang digunakan, dan ban yang digunakan. Sebab itu biaya yang dikerluarkan dapat berbeda jika survei dilaksanakan dengan tipe kendaraan yang berbeda. Sebagai perbandingan dilakukan juga perhitungan dengan menggunakan tipe kendaraan dengan sebaran harga yang berbeda namun kapasitas tampung yang sama yaitu 7 penumpang yang hasilnya dapat dilihat pada lembar lampiran. Pada survei yang dilaksnakan, bahan bakar yang digunakan adalah pertalite karena sebanyak 55\% kendaraan di Jakarta menggunakan bahan bakar pertalite (Sumber: tirto.id), sehingga hasil survei diharapkan dapat mewakili sebagian besar masyarakat di Jakarta. Hasil perhitungan biaya operasi kendaraan dengan metode PCI adalah sebagai berikut:

$\begin{array}{lll}\text { Jarak tempuh } & = & 30 \mathrm{~km} \\ \text { Kecepatan }(\mathrm{S}) & = & 20 \mathrm{~km} / \mathrm{jam} \\ \text { Harga pertalite/liter } & = & \operatorname{Rp~} 7.650 \\ \text { Harga oli/liter } & = & \text { Rp } 78.000 \\ \text { Kendaraan yang digunakan } & = & \text { Chevrolet Spin } 1.5 \mathrm{MT}(2013) \\ \text { Harga kendaraan } & = & \operatorname{Rp~} 178.000 .000 \\ 1 . \text { Konsumsi bbm } & = & 0.03719 \mathrm{~S} * \mathrm{~S}-4.19966 \mathrm{~S}+175.9911 \\ & = & 106,8739 \text { liter } / 1000 \mathrm{~km}\end{array}$

Konsumsi bbm rute Pinang Ranti - Pluit $=3,206217$ liter

Biaya yang dikeluarkan $=\operatorname{Rp~} 7.650 * 3,206217$ liter

$=\quad \operatorname{Rp} 24.527$ 
2. Konsumsi oli mesin $=0.00025 * S^{\wedge} 2-0.02664 * S+1.441710$

$$
=1,00891 \text { liter } 1000 \mathrm{~km}
$$

Konsumsi oli mesin rute Pinang Ranti -Pluit $=0,0302673$ liter

Biaya yang dikeluarkan $\quad=\mathrm{Rp} 78.000 * 0,0302673$ liter $=\mathbf{R p} \mathbf{2 . 3 6 0}$

3. Konsumsi pemakain ban $=0.0008848 * \mathrm{~S}-0.0045333=0,0131627$

Dengan harga ban Rp 520.000/buah = Rp 27.378 /1000 km

Konsumsi ban rute Pinang Ranti-Pluit = Rp 821

4. Biaya Pemeliharaan (onderdil) $=0.0000064 * \mathrm{~S}+0.0005567=0,0006847$

Dengan memasukkan harga kendaraan $\quad=0,0006847 * \mathrm{Rp} 178.000 .000$

$$
=\operatorname{Rp} 121.876 / 1000 \mathrm{~km}
$$

Biaya pemeliharaan rute Pinang Ranti-Pluit $=\mathbf{R p} 3.656$

5. Biaya Pemeliharaan (pekerja) $\quad=0.00362 * S+0.36267=0,43507$

Dengan memasukkan honor montir/jam $=0,43507 * \mathrm{Rp} 17.014=\mathrm{Rp} 7.402 / 1000 \mathrm{~km}$

Biaya pemeliharaan rute Pinang Ranti-Pluit $=\mathbf{R p} 222$

6. Biaya penyusutan Kendaraan $=1 /(2,5 * \mathrm{~S}+125)=0,005714286$

Dengan memasukkan Harga kendaraan $=$ Rp 1.017.142 $/ 1000$ km

Penyusutan kendaraan Rute Pinang Ranti-Pluit = Rp 30.514

7. Suku bunga $=120 /(500 * S)=0,012$

Dengan memasukkan Harga kendaraan = Rp 1.068.000/1000 km

Penyusutan kendaraan Rute Pinang Ranti-Pluit = Rp 32.040

8. Persamaan asuransi $=((35 * 0,5)) /((500 * \mathrm{~S}))=0,00175$

Dengan memasukkan Harga kendaraan $=$ Rp $311.500 / 1000$ km

Penyusutan kendaraan Rute Pinang Ranti-Pluit = Rp 9.345

Total biaya yang dikeluarkan

$=\mathbf{R p} 103.487$

\subsection{Pembahasan}

Dalam penelitian ini, penulis membandingkan waktu perjalanan dan biaya dalam sekali jalan rute dari Pinang Ranti menuju Pluit antara Transjakarta dengan kendaraan pribadi. Tujuannya agar mendapatkan perbandingan dalam kondisi jam sibuk jenis kendaraan mana yang memiliki waktu tempuh yang lebih cepat dan berapa perbandingan biaya yang dikeluarkan antara penggunaan Transjakarta dan kendaraan pribadi. Analisis ini dilakukanan dari sudut pandang masyarakat sehingga dalam perhitungan biaya, jumlah yang dikeluarkan untuk menggunakan Transjakarta hanya harga tiket sedangkan untuk kendaraan pribadi berdasarkan biaya operasional kendaraan. Dari hasil pada Tabel 2 diketahui bahwa waktu perjalanan dengan kendaraan pribadi lebih lama sekitar 11 hingga 
19 menit jika dibandingkan dengan perjalanan Transjakarta rute Pinang Ranti-Pluit. Transjakarta memiliki rata-rata total waktu tempuh 1 jam 13 menit 30 detik pada perjalanan di jam sibuk sore maupun pagi hari.

Selain itu, setelah dilakukan perhitungan terhadap Biaya Operasional Kendaraan (BOK), didapatkan biaya yang perlu dikeluarkan untuk sekali perjalanan adalah Rp 103.487. Jika diasumsikan keadaan kendaraan yang digunakan pada saat survei yaitu Chevrolet Spin 1.5 MT adalah penuh (kapasitas 7 penumpang) maka seorang harus mengeluarkan biaya sebesar Rp 14.784 dalam sekali perjalan rute Pinang Ranti-Pluit dan nominal ini dapat bertambah menjadi Rp 25.871 jika mengacu pada protokol kesehatan yaitu kapasitas saat pandemi maksimal 50\% (4 penumpang). Jika dibandingkan dengan Transjakarta tentu jumlah ini lebih besar karena untuk sekali perjalanan biaya yang dikeluarkan hanya Rp 3.500 per orang jika menggunakan transjakarta.

\section{KESIMPULAN}

Pada penelitian ini dapat diambil kesimpulan bahwa pada jam sibuk penggunaan Transjakarta lebih efektif secara waktu karena waktu tempuh yang diperlukan lebih cepat 11 menit dibandingkan dengan kendaraan pribadi. Sehingga hal tersebut juga berpengaruh terhadap efisiensi nilai waktu pelaku perjalanan jika menggunakan transjakarta. Kemudian untuk biaya yang dikeluarkan juga lebih efisien menggunakan transjakarta. Hasil penelitian ini diharapkan dapat memberikan gambaran kepada masyarakat agar dapat menggunakan transportasi umum dibandingkan mobil pribadi. Penelitian ini dapat disempurnakan oleh para peneliti dibidang transportasi dengan melakukan kajian terhadap mobil pribadi yang bervariasi sehingga nilai BOK yang dihasilkan dapat mewakili seluruh jenis kendaraan pribadi.

\section{DAFTAR PUSTAKA}

[1] A. Utami and H. Widyastuti, "Model Panjang Antrian Kendaraan pada Perlintasan Sebidang Tanpa Palang Pintu (Studi Kasus: Perlintasan Sebidang Jl. Gayung Kebonsari Surabaya)," J. Apl. Tek. Sipil, vol. 17, no. 1, p. 27, 2019.

[2] H. Widyastuti, A. Utami, and M. Putra, "Model of Queuing in the Railway Level Crossings (Case Study: Railway Level Crossings in Jemursari Surabaya)," in Atlantis Press, 2019, vol. 186, no. Apte 2018, pp. 225-232.

[3] S. Octaviani and N. Najid, "Pengaruh Penerapan Erp Terhadap Waktu Tempuh Feeder Dan Waktu Tempuh Perjalanan Ruas Jalan Gatot Subroto," JMTS J. Mitra Tek. Sipil, vol. 3, no. 4, p. 951, 2020.

[4] I. Ismiyati, M. Firdaus, and D. A. Arubusman, "Manajemen Pemeliharaan Bus Transjakarta Dalam Mencapai Standar Pelayanan Minimum," J. Manaj. Transp. Dan Logistik, vol. 3, no. 2, p. 185, 2017.

[5] D. W. Hariyono, "Penyelenggaraan Angkutan Orang dengan Kendaraan Umum di 
Surabaya Implementation of Passenger Transport with Public Transport in Surabaya," J. Manaj. Transp. Logistik, vol. 02, no. 22, pp. 177-190, 2015.

[6] O. Nurahmi and A. A. G. Kartika, "Perbandingan Konstruksi Perkerasan Lentur dan Perkerasan Kaku serta Analisis Ekonominya pada Proyek Pembangunan Jalan Lingkar Mojoagung,” Jur. Tek. Sipil Inst. Teknol. Sepuluh Nop., vol. 1, pp. 63-68, 2012.

[7] R. Rahman, “Analisa Biaya Operasi Kendaraan (BOK) Angkutan Umum Antar Kota dalam Propinsi Rute Palu - Poso," Rekayasa dan Manaj. Transp., vol. 2, no. 1, pp. 8-21, 2012.

[8] R. Achmad Dicky Almansyah, "Perbandingan Biaya Operasional Kendaraan (BOK) dengan Metode Pacific Consultant International (PCI) pada Jalan Lingkar Barat Rogojampi," Universitas Negeri Jember, 2018.

[9] William Kurnia Rubin Natio, "Perencanaan Peningkatan Kinerja dan Analisis Operasional Transjakarta pada Koridor IX (Pinang Ranti-Pluit) pada Masa Pandemi Covid-19.," Universitas Pertamina, 2021.

[10] F. Nurhasanah, "ANALISIS PERPINDAHAN MODA PENGGUNA TRANSJAKARTA TERHADAP MODA MRT FASE II (STUDI KASUS TRANSJAKARTA KORIDOR 1)," Universitas Pertamina, 2021.

[11] W. K. Eko Subandriyo., Ridho Roni Marpaung, Ismiyati, "Jurnal Karya Teknik Sipil," Anal. PERBANDINGAN BIAYA Oper. KENDARAAN JALAN Lingk. AMBARAWA DAN JALAN EKSISTING, vol. 3, no. 4, pp. 356-366, 2014.

[12] N. C. Kresnanto, "Analisis perbandingan bok dan nilai waktu beberapa jenis moda perkotaan,” 19th FSTPT Int. Symp., no. May, pp. 11-13, 2016.

[13] A. Tri Lestari, A. Hasanudin, and W. Kriswardhana, "Hubungan Antara Kerusakan Dalan Dan Biaya Operasional Kendaraan Pada Jalan Kolektor Perkotaan Jember," J. Rekayasa Sipil Dan Lingkung., vol. 2, no. 1, pp. 57-66, 2015.

[14] G. Sumarda, I. B. Indramanik, and P. Sudarma, "Analisis Kinerja Ruas Jalan Dan Perhitungan Biaya Operasional Kendaraan Pada Ruas Simpang Benoa SquareSimpang Tugu Ngurah Rai," Gradien, vol. 10, no. 1, pp. 14-26, 2018. 